\title{
Cerebellar Mutism After Pineal Tumour Excision: A Case Report
}

\author{
Roka YB' ${ }^{1}$, Shrestha $\mathbf{M}^{2}$, Puri PR ${ }^{3}$, Aryal $\mathbf{S}^{4}$ \\ ${ }^{1}$ Dr. Yam Bahadur Roka, MBBS, M.S, M.Ch (Neurosurgery) Chief of Neurosurgery, ${ }^{2}$ Dr. Manzil Shrestha, MBBS, MS, \\ Chief Anaesthesiologist, ${ }^{3}$ Dr. Puspa Raj Puri, MBBS, Medical Officer, ${ }^{4}$ Dr. Sameer Aryal, MBBS, Medical Officer. All \\ from the Neuro Hospital, Biratnagar-13, Nepal.
}

Address for correspondence: Dr. Yam Bahadur Roka, E-mail: dryamroka@yahoo.com

\begin{abstract}
Cerebellar mutism syndrome (CMS) was first described by Rekate et al in 1985. This syndrome is a common complication of posterior fossa surgery in children with range of $11-29 \%$ and usually manifests as diminished speech, hypotonia, and ataxia. The cause is due to bilateral pertubation of the dentate nuclei and their efferent pathways by edema, perfusional defects, axonal damage or metabolic disturbances. Other rare causes of CMS like acute subdural hematoma of the posterior fossa, head injury, brainstem glioma surgery, meningitis and basilar artery occlusion have also been reported. CMS after supracerebellar resection of the pineal tumor is a very rare with very few cases reported. We report such a case in a 10year old boy who underwent excision of a pineal tumor through the infratentorial supracerebellar route.
\end{abstract}

Key Words: Cerebellar mutism, hydrocephalus, pineal tumor, posterior fossa.

\section{Introduction}

$\mathrm{C}$ erebellar mutism syndrome (CMS) was first described by Rekate et al in $1985^{1}$. This syndrome is a common complication of posterior fossa surgery in children with range of $11-29 \%$ and usually manifests as diminished speech, hypotonia, and ataxia. Patients with medulloblastomas with or without brainstem invasion, midline tumors, large tumor size, length of vermian incision and patients with low socioeconomic status are at a greater risk of developing $\mathrm{CMS}^{2,3}$. The cause is due to bilateral pertubation of the dentate nuclei and their efferent pathways by edema, perfusional defects, axonal damage or metabolic disturbances. The sequelae may be permanent if the right cerebellar hemisphere is involved. Other rare causes of CMS like acute subdural hematoma of the posterior fossa, head injury, brainstem glioma surgery, meningitis and basilar artery occlusion have also been reported ${ }^{4,5,6}$. CMS after supracerebellar resection of the pineal tumor is a very rare with very few cases reported ${ }^{7}$.

\section{Case report}

A10-year old male child presented to the emergency with history of severe headache and vomiting for the last 2 months. There was associated difficulty in walking and decreased appetite. On examination the child appeared sick and there was early papilloedema bilaterally with no cranial of motor deficits. The routine hematology and biochemical parameters were normal. Computed tomogram (CT) revealed gross hydrocephalus with an enhancing tumor in the pineal region which was further defined by magnetic resonance imaging (MRI). The tumor was heterogeneously enhancing and displacing the great veins superiorly and compressing the brainstem inferiorly (Figure 1). Infratentorial supracerebellar approach in sitting position along with a right posterior external ventricular drain was used for complete tumor removal with intraoperative problems. Postoperative the child recovered well and was able to ambulate and feed himself after 48 hours. On the fifth postoperative day the child suddenly stopped talking, responding to commands and there was generalized spasticity. There were episodic abnormal cry, shouting, difficulties in swallowing and generalized tonic contractions. Repeat CT showed complete tumor excision, resolution of the hydrocephalus and no postoperative hematoma (Figure 2). No biochemical cause could be found to explain these new onset symptoms. The histopatholgy revealed as a benign pineal gland tumor. A diagnosis of CMS 
was made, the family counseled and he was managed with a nasogastric feeding, physiotherapy and muscle relaxants. The symptoms slowly disappeared and the end of 4 months the child started to respond with return of speech. Presently he is independent in activities of daily life and goes to school but still has learning difficulties.

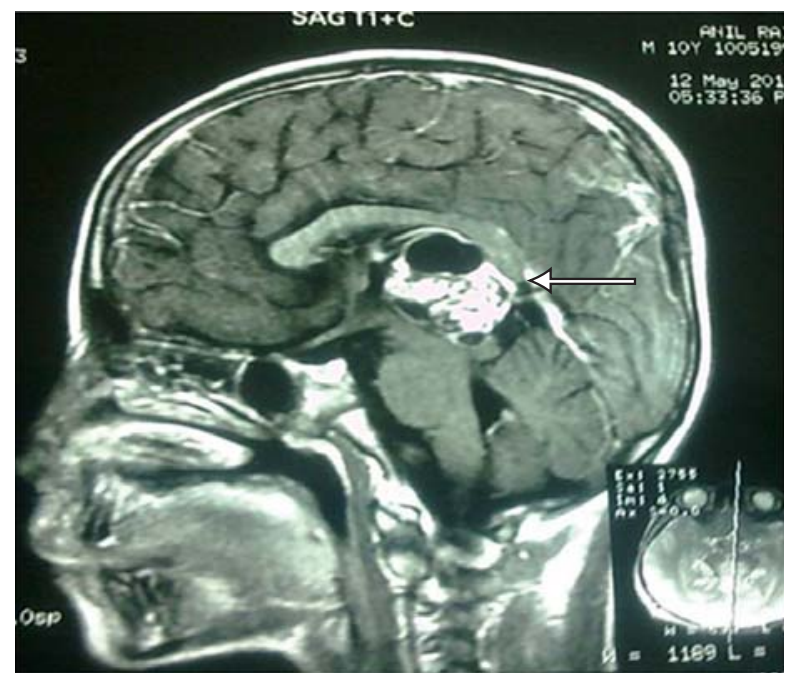

Fig 1: MRI with contrast enhanced T1 sagittal view showing the pineal tumor (white arrow).

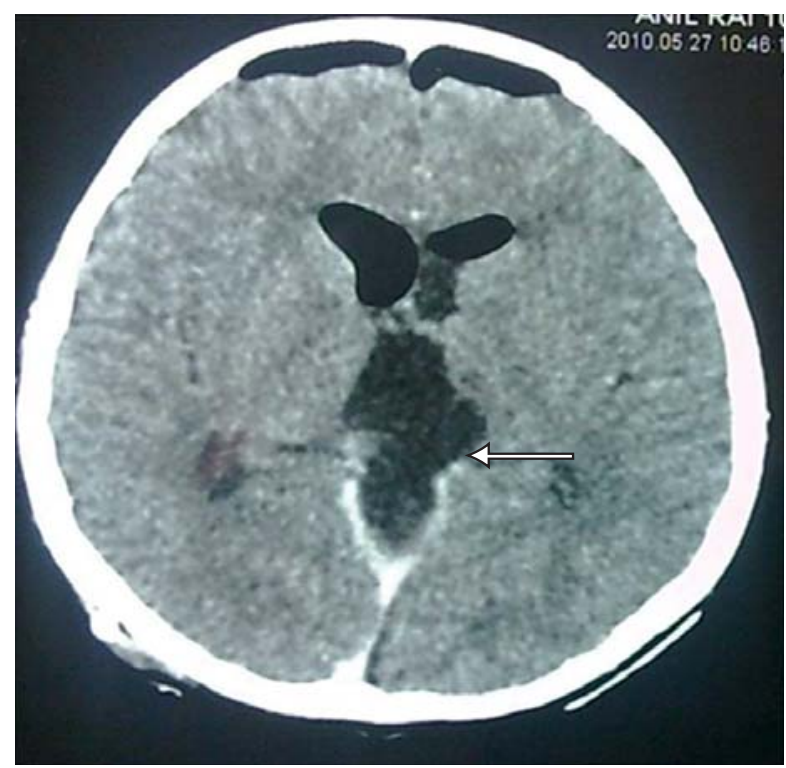

Fig 2: Postoperative plain CT scan with axial section showing complete tumor excision with no residual hematoma (white arrow).

\section{Discussion}

CMS after posterior fossa surgery occurs in $11-29 \%$ of cases and the main cause is damage to the dentate nucleus or its pathways. The symptoms classically start within 48 hours of surgery and subside over several weeks. Cessation of speech, hemiparesis or quadriparesis, excessive crying, emotional instability, dysarthria and ataxia are the hallmark of this syndrome ${ }^{8}$.
Various studies have found abnormalities in the postoperative imaging in the left temporal lobe, the left and right basal nuclei, and the right frontal lobe ${ }^{6,9}$. Speech impairment in CMS can be investigated based on standardized acoustic speech parameters and perceptual criteria and has been divided as dysarthria in post mutistic phase and children with mainly behavioral disturbances ${ }^{10}$. This syndrome has been associated with medulloblastoma and other posterior fossa tumors. CMS after pineal surgery seems to be very rare but as shown by this case is still a probability. The cause may need further investigation but one probable reason may be continued pressure on the cerebellum to cause damage to the superior cerebellar peduncle. Why the CMS developed in this child on the fifth day when he had recovered completely is unknown.

All the neurosurgeons must be aware of CMS and its self limiting course. The family members need to be counseled regarding CMS prior to the surgery. Meticulous technique during surgery and prevention of continued retraction or manipulation of the superior cerebellar peduncle is must to avoid this complication postoperatively.

\section{References}

1. Rekate $\mathrm{HL}$, Grubb RL, Aram DM, Hahn JF, Ratcheson RA. Muteness of cerebellar origin. Arch Neurol 1985; 42:697-8.

2. Gudrunardottir $T$, Sehested A, Juhler $M$, Schmiegelow K. Cerebellar mutism: Review of the literature. Childs Nerv Syst 2010 Nov 9. [Epub ahead of print]

3. Küpeli S, Yalçın B, Bilginer B, Akalan N, Haksal $P$, Büyükpamukçu M. Posterior fossa syndrome after posterior fossa surgery in children with brain tumors. Pediatr Blood Cancer 2010 Oct 25. [Epub ahead of print]

4. Erşahin Y, Mutluer S, Saydam S, Barçin E. Cerebellar mutism: report of two unusual cases and review of the literature. Clin Neurol Neurosurg 1997; 99:130-4.

5. Nishikawa M, Komiyama M, Sakamoto H, Yasui T, Nakajima $\mathrm{H}$. Cerebellar mutism after basilar artery occlusion--case report. Neurol Med Chir (Tokyo) 1998; 38:569-73.

6. Fujisawa $\mathrm{H}$, Yonaha $\mathrm{H}$, Okumoto $\mathrm{K}$, Uehara $\mathrm{H}$, le T, Nagata Y, Suehiro E, Suzuki M. Mutism after evacuation of acute subdural hematoma of the posterior fossa. Childs Nerv Syst 2005; 21:234-6. 
7. Sherman JH, Sheehan JP, Elias WJ, Jane JA Sr. Cerebellar mutism in adults after posterior fossa surgery: a report of 2 cases. Surg Neurol 2005; 63:476-9.

8. Kotil K, Eras M, Akçetin M, Bilge T. Cerebellar mutism following posterior fossa tumor resection in children. Turk Neurosurg 2008; 18:89-94.
9. Catsman-Berrevoets CE, Aarsen FK. The spectrum of neurobehavioural deficits in the Posterior Fossa Syndrome in children after cerebellar tumour surgery. Cortex 2010; 46:933-46.

10. Ozimek A, Richter S, Hein-Kropp C, Schoch B, Gorissen B, Kaiser O, Gizewski E, Ziegler W, Timmann D. Cerebellar mutism--report of four cases. J Neurol 2004; 251:963-72.

\section{How to cite this article?}

Roka YB, Shrestha M, Puri PR, Aryal S. Cerebellar Mutism After Pineal Tumour Excision: A Case Report. J Nep Paedtr Soc 2011;31(2):124-126. 